\title{
Contenidos micro-curriculares en educación ambiental, para promover la responsabilidad social en educación media
}

\author{
Format and content criteria in peer review of academic texts with university students
Critérios de formato e conteúdo na revisão por pares de textos acadêmicos com estudantes universitários

ARTÍCULO DE INVESTIGACIÓN

\section{Johana Estrada Estrada \\ nataly_e88@hotmail.com \\ ORCID: 0000-0001-7995-5683}

Universidad Nacional De Rosario - Argentina

Irene Caguano Romancela

irenecaguano@hotmail.com

ORCID: 0000-0001-6665-4910

Universidad Yacambú - Venezuela
Raúl Benavides Lara

raulbenavideslara@yahoo.com

ORCID: 0000-0001-5560-845X

\section{Escuela Superior Politécnica} de Chimborazo - Ecuador

Víctor Usca Pinduisaca

tino1320@hotmail.es

ORCID: 0000-0002-1553-2523

Escuela Superior Politécnica de Chimborazo - Ecuador

Recibido 01 de febrero 2021 | Arbitrado y aceptado 16 de febrero 2021 | Publicado en marzo 2021

\section{RESUMEN}

La educación ambiental procura la toma de conciencia para el desarrollo humano sustentable, en armonía con la naturaleza, la educación media debe contribuir con esta concientización. El objetivo de este artículo es proponer contenidos microcurriculares en Educación Ambiental para promover la Responsabilidad Social en estudiantes de Educación Media. El método es cuantitativo, para la recolección de datos se utilizaron cuestionarios aplicados a estudiantes y docentes. Los resultados muestran que los estudiantes no reciben formación suficiente en el área de Educación Ambiental. Los docentes reconocen la necesidad de incluir contenidos micro-curriculares en otras asignaturas para mejorar la formación en educación ambiental y crear una cultura de responsabilidad social con el medio ambiente. Se concluye que es necesaria la inclusión de contenidos micro-curriculares en las asignaturas Biología y Química para el tratamiento del tema de Educación Ambiental y Responsabilidad Social y la concientización de docentes, instituciones educativas y Ministerio de Educación.

Palabras clave: Contenidos micro-curriculares; educación ambiental; responsabilidad social

\begin{abstract}
Environmental education seeks to raise awareness for sustainable human development, in harmony with nature, secondary education should contribute to this awareness. The objective of this article is to propose micro-curricular contents in Environmental Education to promote Social Responsibility in High School students. The method is quantitative, for data collection questionnaires applied to students and teachers were used. The results show that students do not receive sufficient training in the area of Environmental Education. Teachers recognize the need to include microcurricular content in other subjects to improve training in environmental education and create a culture of social responsibility with the environment. It is concluded that it is necessary to include microcurricular content in the subjects Biology and Chemistry for the treatment of the subject of Environmental Education and Social Responsibility and the awareness of teachers, educational institutions and the Ministry of Education.
\end{abstract}

Key words: Micro-curricular Content; environmental education; social responsibility 


\section{RESUMO}

A educação ambiental busca a conscientização para o desenvolvimento humano sustentável, em harmonia com a natureza, o ensino médio deve contribuir para essa conscientização. 0 objetivo deste artigo é propor conteúdos microcurriculares em Educação Ambiental para a promoção da Responsabilidade Social em alunos do Ensino Médio. 0 método é quantitativo, para a coleta de dados foram utilizados questionários aplicados a alunos e professores. Os resultados mostram que os alunos não recebem formação suficiente na área de Educação Ambiental. Os professores reconhecem a necessidade de incluir conteúdos microcurriculares em outras disciplinas para aprimorar a formação em educação ambiental e criar uma cultura de responsabilidade social com o meio ambiente. Conclui-se que é necessária a inclusão de conteúdo microcurriculares nas disciplinas de Biologia e Química para o tratamento da disciplina de Educação Ambiental e Responsabilidade Social e a sensibilização de professores, instituições de ensino e Ministério da Educação

Palavras-chave: Conteúdos microcurriculares; educação ambiental; responsabilidade social

\section{INTRODUCCIÓN}

La problemática ambiental a nivel mundial, en los tiempos actuales es diversa, no sólo se limita a la prevención de la extinción de especies vivas, sino a aspectos más complejos como reducir el calentamiento global, disminuir los efectos de la destrucción de la capa de ozono; así como también la contaminación de las aguas y el paisaje, la erosión del suelo y la atmósfera, la destrucción del patrimonio histórico-cultural (Avendaño, 2012).

La tarea principal de la educación en un país debe ser la transformación la sociedad, con miras a mejorar las relaciones entre los hombres y su relación con el ambiente. La educación ambiental procura la toma de conciencia encaminada a conseguir el anhelado desarrollo humano sustentable y en armonía con la naturaleza. En Ecuador, se ha evidenciado el mal uso de los recursos naturales a través de la deforestación y tala indiscriminada de bosques, contaminación de las aguas, los suelos y el aire, erosión, pérdida de biodiversidad y recursos genéticos, el deficiente manejo de desechos, inadecuado tratamiento de aguas servidas, mala recolección y tratamiento de la basura, el deterioro de las condiciones ambientales urbanas (Da Ros, 1995; Noboa, 2003).

Lo que acontece en Ecuador es la evidencia a nivel macro de lo que sucede en las escuelas en relación al tema ambiental. El Estado ecuatoriano, a través del Ministerio de Educación, diseña y valida el currículo educativo para las diversas instituciones del país. Al finalizar la Educación General Básica (EGB) los estudiantes continúan con su formación en el Bachillerato General Unificado (BGU), enmarcados en un currículo con contenidos específicos de las áreas básicas, evidenciando la ausencia de contenidos específicos en Educación Ambiental, lo cual desencadena en la falta de conciencia de los estudiantes en su manera de actuar frente al uso de los recursos naturales.

La escases de contenidos de educación ambiental en el currículo del BGU, se pone en evidencia en las conductas estudiantiles que muestran que no existe un comportamiento adecuado en actividades básicas cotidianas como ahorro del agua, energía eléctrica, manejo adecuado de desechos, sus acciones se limitan a realizar actividades comunes de cuidado medioambiental como colocar la basura en su lugar y al cuidado de las plantas, sin embargo, existen muchas otras actividades que los estudiantes no practican, por lo cual es necesario incentivar y educar respecto a estos temas; que contribuyen a tener un ambiente más saludable, menos contaminado, y cuidando los recursos naturales para poder prolongar la vida de nuestro planeta.

Con respecto a esta problemática es importante que se fomente una visión 
integradora entre la educación general y la educación ambiental, con la finalidad de transcender la disciplinariedad hacia un currículo interdisciplinario y transdisciplinario (Paucar, 2012). Es por eso que se considera que el problema radica en la falta de educación, concienciación, empoderamiento y la aplicación de la responsabilidad social de los estudiantes, frente a su medio ambiente, por lo tanto, la propuesta alude a incluir temas de educación ambiental y responsabilidad social con el ambiente, en el currículo de manera transversal e integradora.

Ante esta situación es pertinente preguntarse, ¿qué aspectos debe abordar una propuesta de contenidos micro-curriculares en educación ambiental para promover la responsabilidad social en estudiantes de educación media?, ¿existen contenidos microcurriculares del BGU en relación a los temas de educación ambiental y responsabilidad social?, ¿cuáles serían esos contenidos y serán suficientes?, ¿Qué contenidos microcurriculares de educación ambiental serán necesarios incluir para fomentar la responsabilidad social en los estudiantes?, ¿cuál es la percepción de los estudiantes y docentes sobre la educación ambiental y la responsabilidad social en el BGU?.

La presente investigación es considerada de importancia práctica, puesto que se orienta a proponer mejoras dentro del currículo del BGU, de importancia ambiental ya que contribuye a mejorar la relación del ser humano con el ambiente, de relevancia educativa, puesto que propone la visión inter y transdisciplinario del currículo educativo en el tema de educación ambiental y responsabilidad social, por lo demás constituye un aporte a los temas de educación ambiental en general $y$ específicamente de responsabilidad social ambiental el cual es un tema de reciente data.
El objetivo de esta investigación es proponer los contenidos micro-curriculares en Educación Ambiental para promover la Responsabilidad Social en estudiantes de Educación Media. Para el desarrollo de este objetivo se plantean los siguientes objetivos específicos: 1) Analizar los contenidos microcurriculares del Bachillerato General Unificado en relación a los temas de Educación Ambiental y Responsabilidad Social (BGU), 2) Determinar los contenidos micro-curriculares de Educación Ambiental necesarios que se requieren incluir para fomentar la Responsabilidad Social, 3) Conocer la percepción de los estudiantes y docentes sobre la Educación Ambiental y Responsabilidad Social en el BGU.

Para el desarrollo de los objetivos se requiere aclarar desde el punto de vista teóricoconceptual las definiciones de planificación curricular y los tipos de planificación curricular, lo que se entiende por educación ambiental y responsabilidad social. Según el Ministerio de Educación (2016) la Planificación Curricular se trata de: "lineamientos para adaptar y delimitar la estructura, temporalidad, seguimiento $\mathrm{y}$ evaluación de los documentos de planificación que la institución utilizará en la práctica pedagógica”. (p. 9). En el artículo 9 del Acuerdo Ministerial № ME-2015-00168-A de 01-122015, señala que para el cumplimiento de la diversidad establecida en el marco legal educativo, se requiere que exista una distribución de responsabilidades en el desarrollo del diseño curricular. Este comprende tres niveles de concreción y se señalan a continuación:

Por su parte, la planificación macrocurricular, es un tipo de planificación que está elaborada por un conjunto de expertos en las áreas del conocimiento, entre los cuales se puede mencionar a los distintos docentes que laboran en las áreas de educación, pedagogía, 
currículo y otras más. Aquí se especifica el perfil de salida del bachiller, los objetivos, las destrezas con criterios de desempeño, los indicadores de evaluación; requisitos que son obligatorios a nivel nacional. En el currículo nacional, se encuentran plasmadas las políticas que se generan mediante la Autoridad Educativa Nacional. El currículo es flexible y abierto, permite a las instituciones educativas y a los equipos de docentes definir, a partir de lo establecido, los contenidos que correspondan a las necesidades e intereses de los estudiantes, y que estén acordes con la realidad institucional y de la comunidad. (Ministerio de Educación, 2016).

La planificación meso-curricular, comprende dos subtipos de planificaciones más, que son: la Planificación Curricular Institucional (PCI) y la Planificación Curricular Anual (PCA). Ambas planificaciones, se elaboran de una manera armónica entre las autoridades y docentes de cada institución; en donde se debe responder a las especificidades y al contexto institucional, así como a la pertinencia cultural propia de los pueblos y nacionalidades indígenas. (Ministerio de Educación, 2016).

Por planificación micro-curricular o planificación de aula, se entiende, según el Ministerio de Educación (2016), a un documento de uso interno en cada institución educativa, la cual diseña de manera autónoma, sus formatos de planificación en el tercer nivel de concreción, en el que se expresan los objetivos y contenidos de la clase, la metodología, recursos y las estrategias de evaluación.

La planificación micro-curricular o también conocida como planificación de aula, es elaborada por los docentes de grado, para el desarrollo de los aprendizajes a nivel del aula; este tipo de planificación, pretende que el docente conozca y maneje acertadamente los programas de estudio y de esta manera poder escoger una serie de actividades adecuadas para que todos los estudiantes adquieran mejor sus aprendizajes (Ministerio de Educación, 2016). La planificación micro-curricular requiere que se usen el máximo de elementos para orientar el trabajo del docente, con buenas actividades de aprendizaje. La planificación micro-curricular es una excelente herramienta de trabajo, ya que ayuda a evitar la improvisación innecesaria y constituye un buen referente para el seguimiento curricular.

Con respecto a la Educación Ambiental y del Medio Ambiente se puede encontrar una serie de definiciones. Teóricamente se ha hablado mucho pero se ha hecho poco en la práctica, claro que cada día nos encontramos con mayores deterioros, los sistemas educativos en diversos países deben propender que la actual educación sea vivencial y cada vez más práctica. El ser humano no es el dueño de toda la naturaleza y como somos parte muy influyente de ello estamos obligados a cuidar, conservar y respetar todas las formas de vida, así como todos los recursos, mejorando nuestra actitud que amenaza al equilibrio natural. (Gutiérrez y Pozo, 2006).

Según Tello y Pardo (1996) la educación ambiental debe ser una educación orientada a capacitar personas en acciones racionales $\mathrm{y}$ autónomas, fundamentadas en valores, eliminación de conductas negativas y modificación de actitudes que conduzcan a identificarse con la problemática ambiental en los niveles globales y locales; al tiempo que se desarrolla el sentido de protección, preservación y conservación de los sistemas de soporte vital del planeta, lo cual se dirige al desarrollo sostenible para la garantía del sostenimiento y calidad de vida de múltiples generaciones.

Se trata así, que los sistemas educativos, desde la etapa inicial, hasta el bachillerato y universidades, incluyan la educación 
ambiental, ya sea como una asignatura o como un eje transversal incorporado en las planificaciones micro-curriculares de manera de, contribuir a la formación constante en la protección, preservación y conservación del ambiente para el desarrollo sostenible.

De acuerdo a la cronología, la educación ambiental toma interés a inicio de la década de los setenta, por iniciativa de organismos internacionales como el Consejo para la Educación Ambiental, en el que se plantea como propuesta para orientar a la población, la necesidad de organizar procesos educativos con la finalidad de alcanzar los objetivos trazados en los diferentes acuerdos. Los convenios internacionales que sirven para proteger el medio ambiente, buscan cambiar el comportamiento del ser humano frente a la actitud depredadora que pone en riesgo su supervivencia y de las especies que habitan en su entorno natural. (Alea, 2005). Desde entonces la sociedad empieza a tomar conciencia de la problemática ambiental y Educación Ambiental surge como respuesta educativa a los mismos.

Para cerrar este punto, se aborda el tema de la responsabilidad social. Responsabilidad significa hacer bien las cosas que nos competen sin necesidad de que nadie nos lo diga y asumiendo las consecuencias de nuestros actos; es un compromiso que adquirimos por hacer bien las cosas, para responder adecuadamente a las obligaciones y expectativas de la vida.

Carneiro (2004) define la responsabilidad social como la unificación discrecional de las personas, empresas o instituciones, en torno a las inquietudes sociales y morales, que llevan a tomar conciencia de las consecuencias de sus acciones sobre el entorno social; internalizando pautas de comportamiento positivo en consonancia con los valores e intereses sociales.

A la responsabilidad social se la puede entender como una obligación ética y moral que se asume de manera voluntaria, para insertarse en el marco social y está directamente ligada al desarrollo sostenible de cualquier sociedad. Para Valleys F. (como se citó en Benavides, 2014) la responsabilidad social es una exigencia ética al tiempo que es una estrategia racional de desarrollo que contribuye a la inteligencia organizacional, en la medida que exige a las organizaciones ser responsables de sus acciones y consecuencias con el entorno y ofrecer respuestas a los grupos implicados o afectados por dichas acciones y consecuencias.

Ahora bien, la responsabilidad social puede generarse desde varios escenarios, se puede hablar de responsabilidad social en ámbito el empresarial, institucional $y$ en el medio ambiente, a los fines del presente trabajo interesa destacar este último aspecto. Para Carneiro (2004) "La Responsabilidad Social con el Medio Ambiente es el nexo de conexión con el planteamiento más ambicioso del desarrollo sostenible. Corresponde a la obligación que mantiene cuidar y preservar tanto el entorno como la naturaleza en su conjunto". (pág. 34). Hoy en día la responsabilidad social es un tema que ha ido creciendo en el medio, debido al impacto ambiental ocasionado por las industrias $\mathrm{y}$ en menor medida el uso inadecuado de aparatos dentro del hogar y la escuela.

\section{MÉTODO}

La investigación fue elaborada según las siguientes fases propuestas por Albert Gómez (2007) que se muestran a continuación: a.Fase Preparatoria. b.- Fase de Trabajo de Campo. c.- Fase analítica. d.- Fase informativa y elaboración del informe. Incluye la elaboración de la propuesta de contenidos microcurriculares en Educación Ambiental, para promover la Responsabilidad Social en los estudiantes del BGU y las conclusiones y recomendaciones. 
La presente investigación fue inductiva y cuantitativa. La población definida fue de 175 jóvenes entre 15 y 17 años de edad y 40 docentes. La definición de la muestra corresponde a 120 estudiantes del BGU y los 40 docentes que corresponden al total de la población ya que no es un número representativo.

Se aplicó el cuestionario como instrumento de recolección de datos, previamente validados por expertos, se utilizaron dos cuestionarios, uno administrado a estudiantes $\mathrm{y}$ otro a docentes. El cuestionario administrado a los estudiantes constó de 12 preguntas cerradas, dicotómicas y de selección múltiple sobre los temas de Educación Ambiental y Responsabilidad Social. El otro cuestionario destinado al personal docente con un total de 15 preguntas cerradas; tanto dicotómicas como de selección múltiple.

El procesamiento de información, se realizó con el programa informático SPSS 22, en donde además se realizaron los cálculos y se diseñaron los gráficos correspondientes, para luego realizar el respectivo análisis e interpretación de cada uno.

\section{RESULTADOS}

En este apartado se presentan los resultados de los cuestionarios aplicados como lo son lo relativo a los contenidos microcurriculares, los datos de los estudiantes, la educación ambiental y la responsabilidad social desde la perspectiva de los estudiantes, los datos de los docentes encuestados, los contenidos micro-curriculares, la educación ambiental y la responsabilidad social desde la perspectiva de los docentes. Se finalizan los resultados del estudio con la propuesta de contenidos micro-curriculares en educación ambiental, para promover la responsabilidad social en los estudiantes de educación media.
Como resultado del objetivo planteado en cuanto al análisis los contenidos microcurriculares del Bachillerato General Unificado en relación a los temas de Educación Ambiental y Responsabilidad Social (BGU), se tiene:

El currículo actual que el Ministerio de Educación, maneja para el Bachillerato General Unificado (BGU) menciona que las asignaturas que se dictan en el BGU, se derivan de las materias principales que son consideradas como base, para desprender los contenidos que se enseñarán a los estudiantes. Estas materias principales son: Matemáticas, Lengua y Literatura, Ciencias Sociales y Ciencias Naturales. La asignatura de Ciencias Naturales, se imparte como tal durante toda la Educación General Básica, dividida en bloques, y estos bloques divididos en varios sub-bloques, que contienen temas relacionados a la asignatura.

Una vez culminada la Educación General Básica, los estudiantes pasan al nivel del Bachillerato General Unificado, donde específicamente la asignatura de Ciencias Naturales, desprende tres materias que son: Física, Biología y Química.

Como se observa en la Figura 1, la asignatura de Ciencias Naturales consta de cinco bloques que se imparten durante toda la Educación General Básica. A su vez el Bloque 1 y 2 , se divide en cuatro sub-bloques que forman parte de la asignatura de Biología. El bloque tres de la asignatura de Ciencias Naturales, se divide en dos sub-bloques que forman parte de la asignatura de Química y cuatro sub-bloques que forman parte de la asignatura de Física. El bloque cuatro de la asignatura de Ciencias Naturales, también es parte de la asignatura de Física. Y el bloque cinco de la asignatura de ciencias Naturales, se encuentra en cada una de las asignaturas, es decir en Biología, en Química y en Física, hay un sub-bloque más (Ministerio de Educación y Cultura, 2016). 


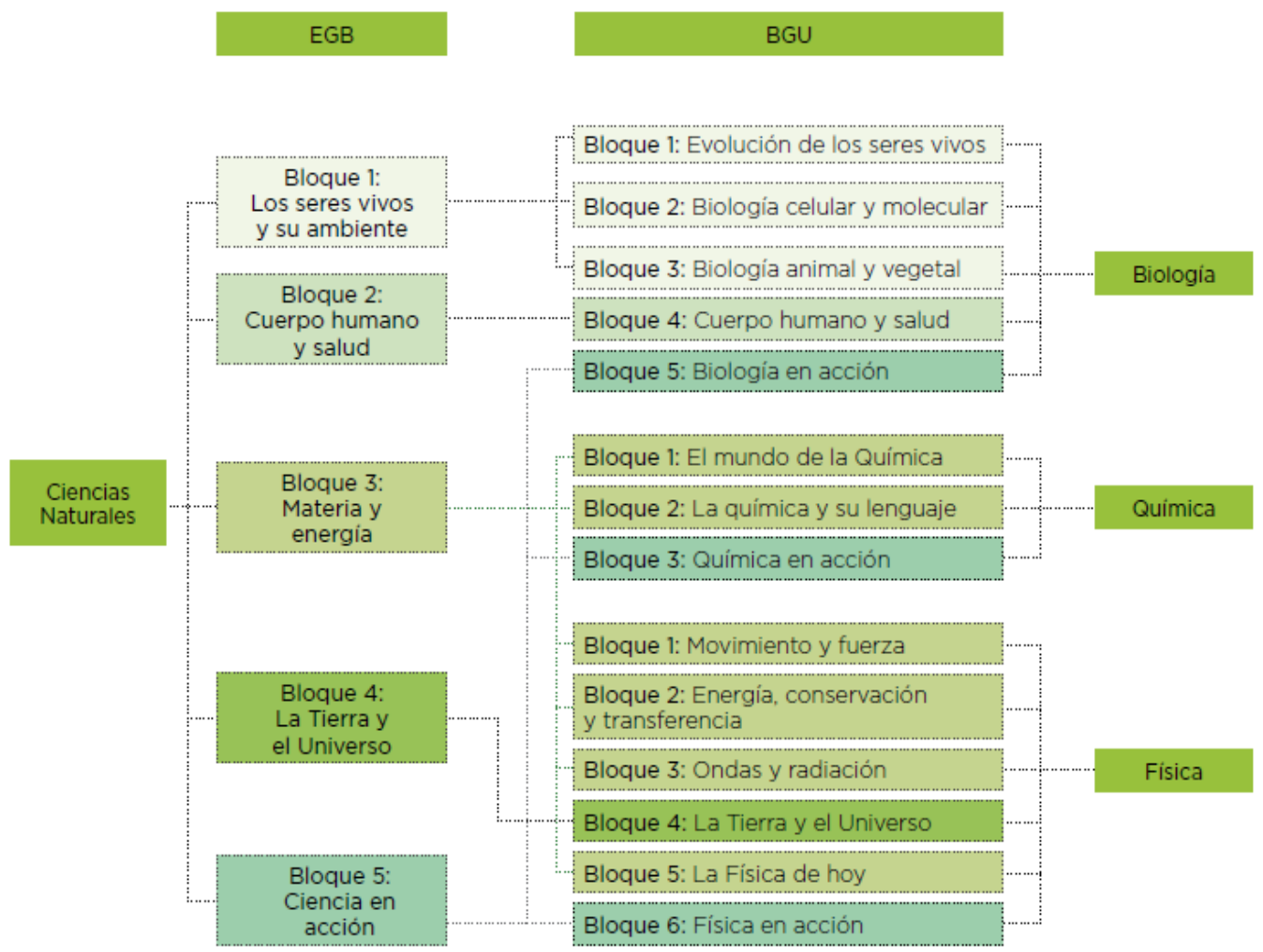

Figura 1. Organización de la asignatura de Ciencias Naturales. Fuente: Ministerio de Educación y Cultura (2016).

En relación al objetivo de conocer la percepción de los estudiantes sobre la Educación Ambiental y Responsabilidad Social en el BGU, se obtuvieron los siguientes resultados:

En cuanto a los datos generales de los estudiantes, específicamente la variable año de estudio (ver Gráfico 1) se puede observar que de la muestra de 120 estudiantes que pertenecen al BGU, se encuestó a 70 estudiantes de primero (58,3\%), 43 estudiantes de segundo $(35,8 \%)$ y 7 estudiantes de tercero $(5,8 \%)$, es decir que la mayor parte de estudiantes encuestados se encuentra concentrada en el primer año de Bachillerato General Unificado. 


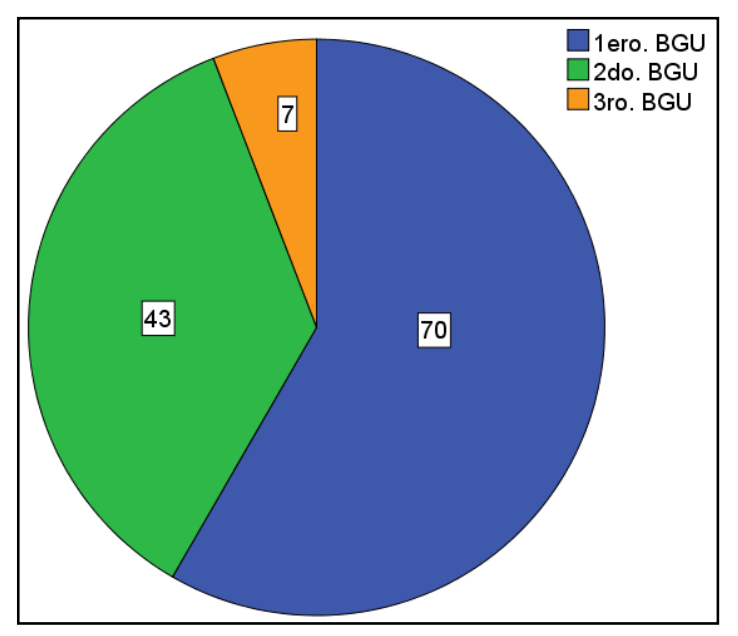

Gráfico 1. Año de Estudio.

Referidos al tema de educación ambiental, se preguntó a cada estudiante si ¿había recibido en su institución algún tema o contenido sobre Educación Ambiental? De la muestra de 120 estudiantes que pertenecen al BGU, 101 estudiantes contestaron que NO han recibido en su institución algún tema o contenidos sobre Educación Ambiental lo que representó un 84,2\%, mientras que 19 estudiantes contestaron SI haber recibido es decir el 15,8\% SI recibió, se deduce que 10 de cada 12 estudiantes encuestados, aseguran no haber recibido algún tema o contenido de Educación Ambiental (ver Gráfico 2).

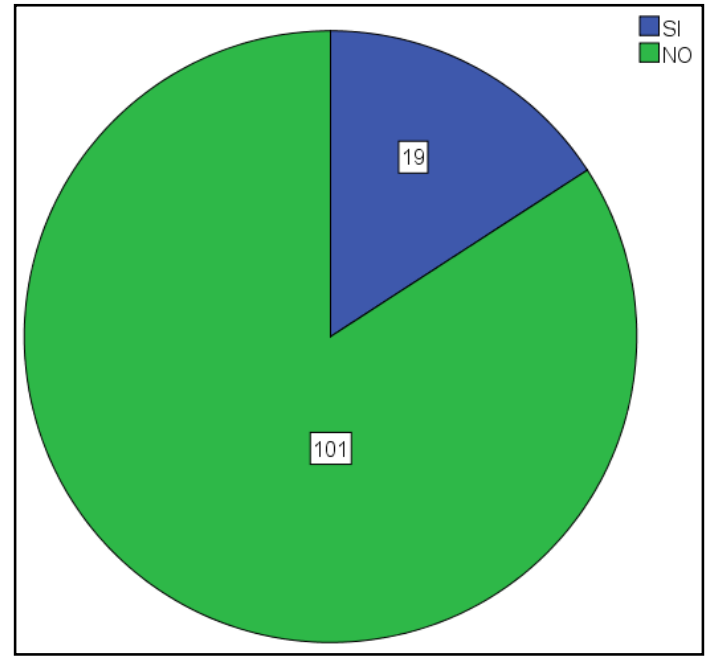

Gráfico 1. Contenido recibido sobre Educación Ambiental

Otra pregunta interesante dirigida a los estudiantes fue que si ¿Considera que es importante profundizar en temas de Educación Ambiental? De los 120 estudiantes, 114 afirmaron que SI es importante profundizar en temas de Educación Ambiental (95\%), mientras que 6 estudiantes contestaron que NO era importante (5\%) (Ver gráfico 3). 


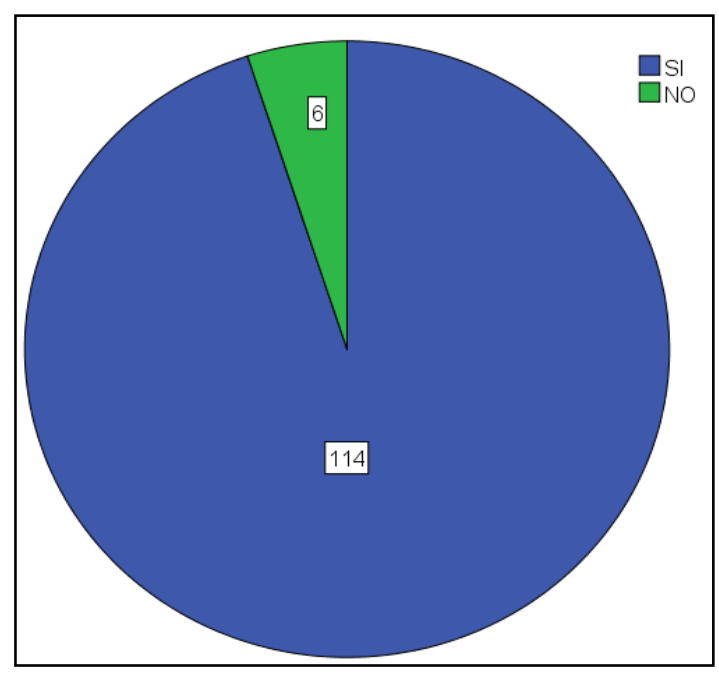

Gráfico 3. Profundización en temas de Educación Ambiental

Ante la pregunta ¿Cómo le gustaría que fueran las clases de Educación Ambiental? De la muestra de 120 estudiantes que pertenecen al BGU, 68 estudiantes contestaron que las clases les gustaría que fueran tanto teóricas como prácticas (56,7\%), mientras que 48 estudiantes contestaron que las clases deben ser solamente prácticas (40\%) y 4 estudiantes contestaron que las clases deben ser solamente teóricas (3,3\%). Por lo tanto, se deduce que 6 de cada 12 estudiantes encuestados, aseguraron que les gustaría recibir clases de Educación Ambiental de una manera práctica y teórica (ver gráfico 4).

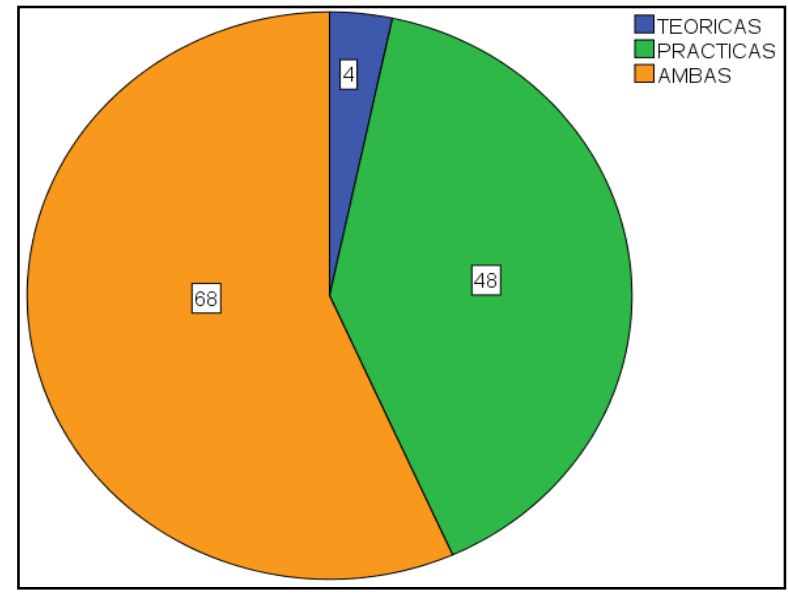

Gráfico 4. Tipo de contenido de las clases de Educación Ambiental.

En lo que se refiere a los conocimientos que tienen los estudiantes referentes a temas ambientales, 8 de cada 10 dice que sabe MUCHO sobre contaminación del agua. En el resto de temas los estudiantes dicen conocer POCO acerca de ellos. Esto lleva a concluir que los jóvenes si requieren de una enseñanza más profunda, sobre cuidado medioambiental. En definitiva, los resultados obtenidos en las encuestas respeto a los temas de Educación Ambiental, muestran 
que los estudiantes reciben muy pocos conocimientos en este tema y que es necesario profundizarlos. Para lo cual se considera que las asignaturas de Biología y Química, son las apropiadas para incluir los temas a la Educación Ambiental (ver gráfico 5).

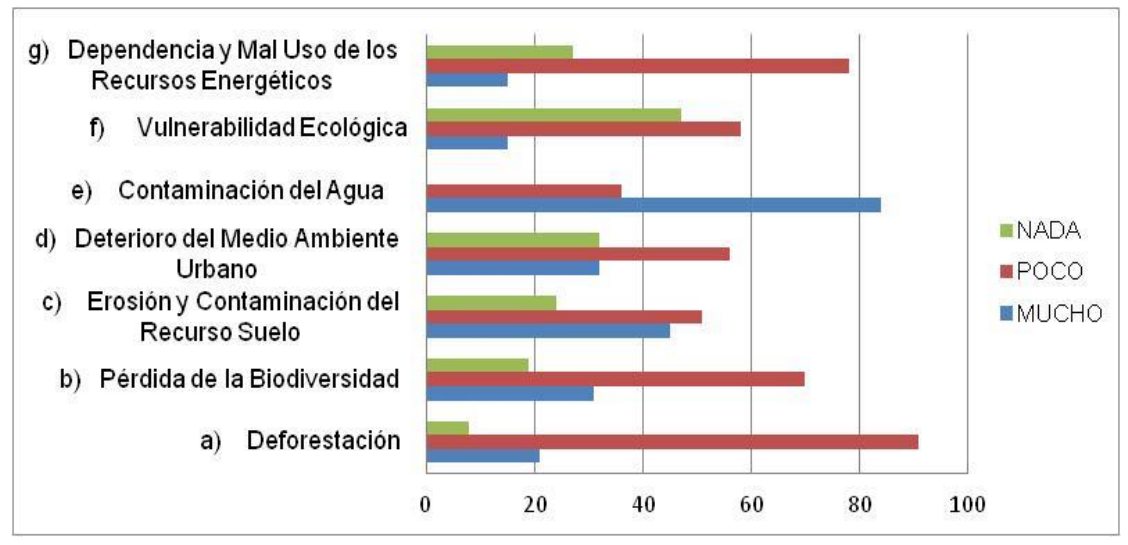

Gráfico 5. Conocimiento sobre Problemas Ambientales

En relación a las respuestas a las preguntas sobre Responsabilidad Social se le preguntó a los estudiantes ¿con qué frecuencia realizaba las siguientes actividades dentro de la Institución? (ver gráfico 6), los resultados arrojaron que en lo que se refiere a las actividades para cuidar el medio ambiente, 7 de cada 10 cuida las plantas y bota la basura en su lugar, el resto de las actividades lo realizan muy poco, lo que significa que hace falta crear una cultura de Responsabilidad Social para cuidar mejor el medio ambiente institucional.

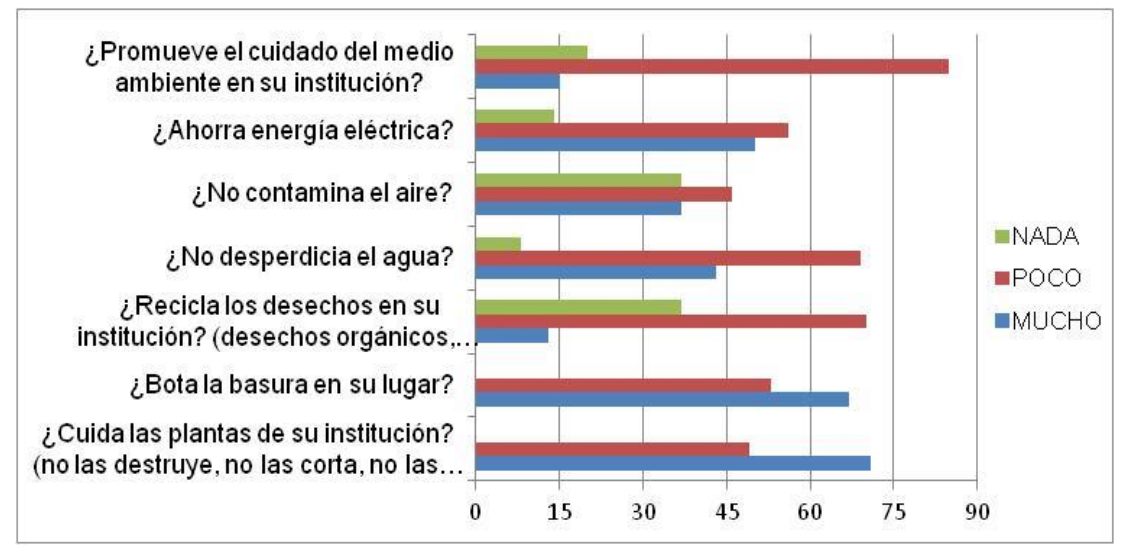

Gráfico 6. Frecuencia de actividades ambientales dentro de la Institución.

Ahora bien, de las encuestas realizadas al personal docente, sobre la percepción en temas de contenidos micro-curriculares, educación ambiental y responsabilidad social, se pudo obtener los siguientes resultados: 
En relación a datos generales del personal docente se pudo observar que la muestra de 40 docentes encuestados, 27 son de género masculino y 13 son de género femenino. Que representan un 67,5\% masculino y 32,5\% femenino. Es decir que 7 de cada 10 docentes son de género masculino (ver gráfico 7).

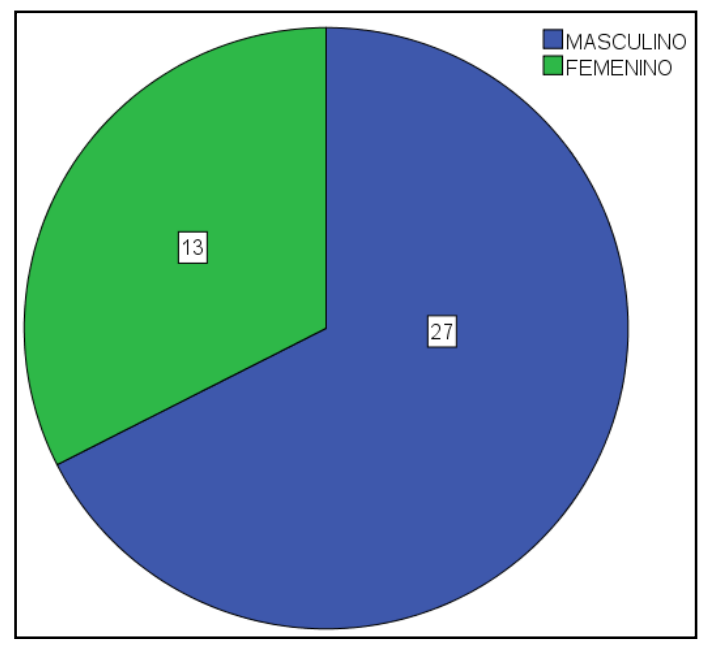

Gráfico 7: Género de los Docentes.

Otro dato general de los docentes son los años de servicio en la institución educativa. Se pudo observar que de la muestra de 40 docentes encuestados, 17 docentes han trabajado 3 años (42,5\%), 11 docentes han trabajado 1 año (27,5\%), 4 docentes han trabajado 5 años (10\%), 3 docentes han trabajado 15 años (7,50\%), 3 docentes han trabajado 0 años $(7,50 \%)$ y 2 docentes han trabajado 7 años (5\%), es decir, que 4 de cada 10 docentes tenían una experiencia de 3 años en la docencia educativa (ver gráfico 8).

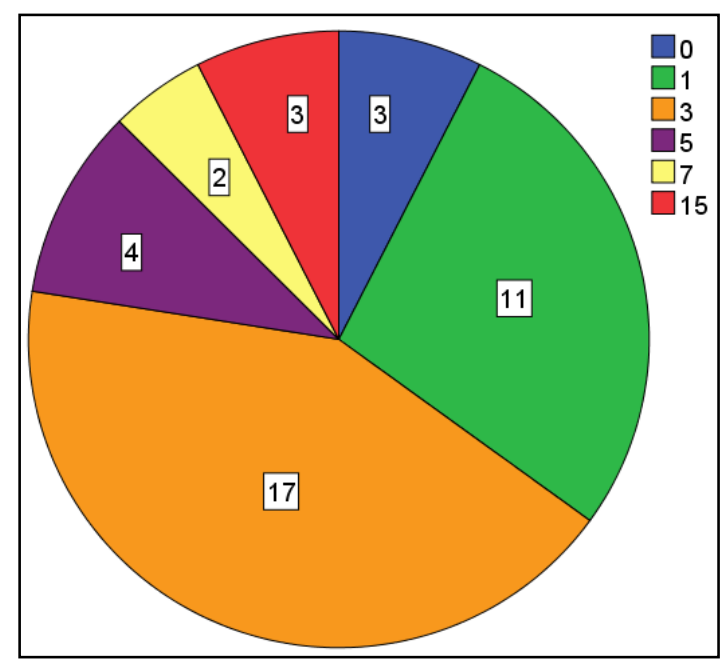

Gráfico 8. Años de trabajo en la Unidad Educativa "Carlos Cisneros". 
Con referencia a la opinión sobre los contenidos micro-curriculares sobre educación ambiental, se le realizó a los docentes la siguiente pregunta ¿considera usted que en el Currículo del BGU, existen contenidos programáticos de Educación Ambiental? (ver gráfico 9). Se pudo obtener de la muestra de 40 docentes encuestados, 21 docentes consideraron que en el Currículo del BGU, NO existen contenidos programáticos de Educación Ambiental, mientras que 19 docentes consideran que Si existen contenidos de Educación Ambiental. Que representan un 52,5\% en NO y 47,5\% en SI. Es decir que casi la mitad de los docentes conocen que si existen contenidos de Educación Ambiental pero que no son profundizados, por esta razón los estudiantes no recuerdan haber recibido estos temas.

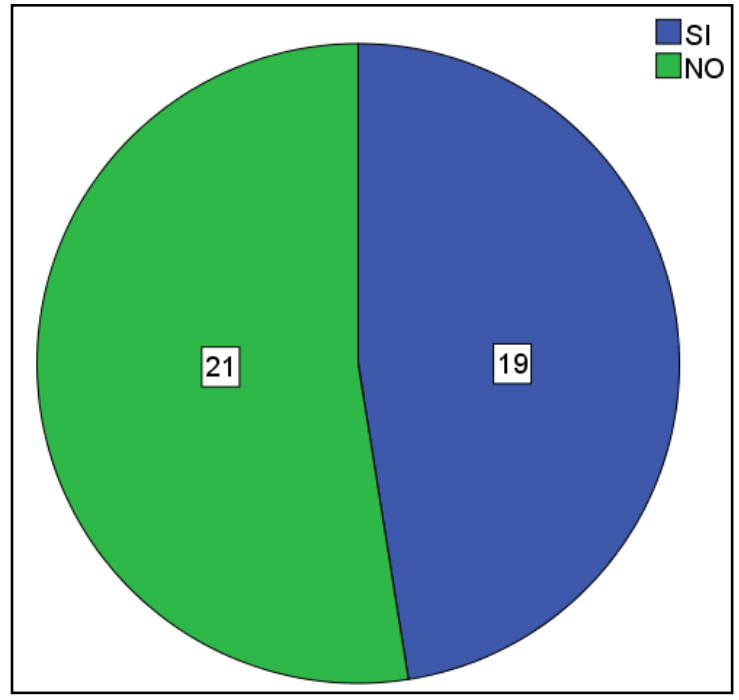

Gráfico 9. Contenidos programáticos de Educación Ambiental.

Seguidamente se preguntó a los docentes si ¿en las asignaturas que imparte, contempla algún tema o unidad referente a Educación Ambiental? De la muestra de 40 docentes encuestados, 25 docentes consideraron que en las asignaturas que ellos imparten SI se contempla algún tema de Educación Ambiental (62,5\%), mientras que 15 docentes consideran que No contemplan contenidos de Educación Ambiental (37,5\%) (Ver gráfico 10). 


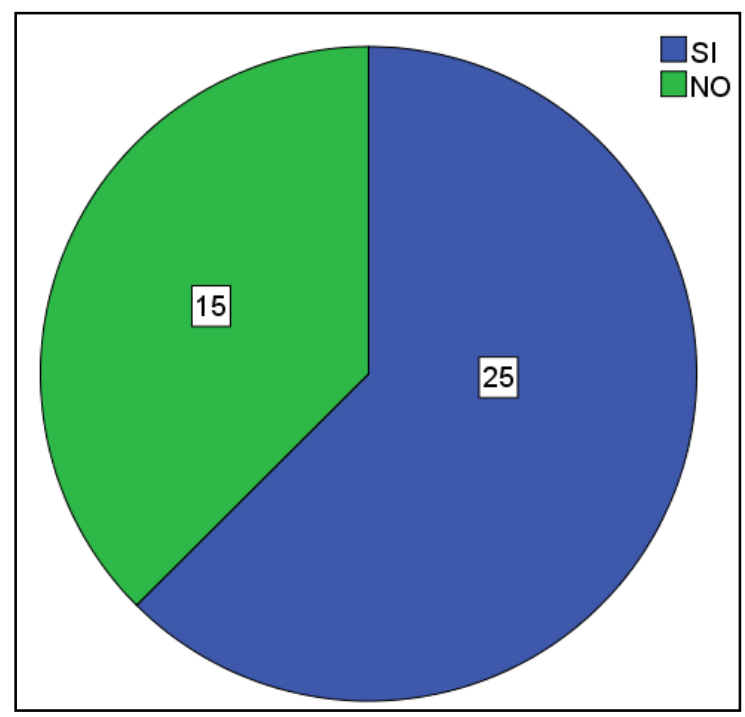

Gráfico 10. Tema de Educación Ambiental en las Asignaturas

En cuanto a la opinión de los docentes sobre temas de educación ambiental si deben ser contenidos teóricos o actividades prácticas se tiene que 38 docentes consideran que la Educación Ambiental debe ser Teórica y Práctica (95\%), mientras que 2 docentes consideran que debe ser Teórica (5\%). Es decir que 9 de cada 10 docentes consideran que las clases de Educación Ambiental deberían ser tanto teóricas como prácticas (ver gráfico 11). Y al igual que los estudiantes, consideraron que una manera de promover su interés por estos temas, debe ligarse la teoría con la práctica.

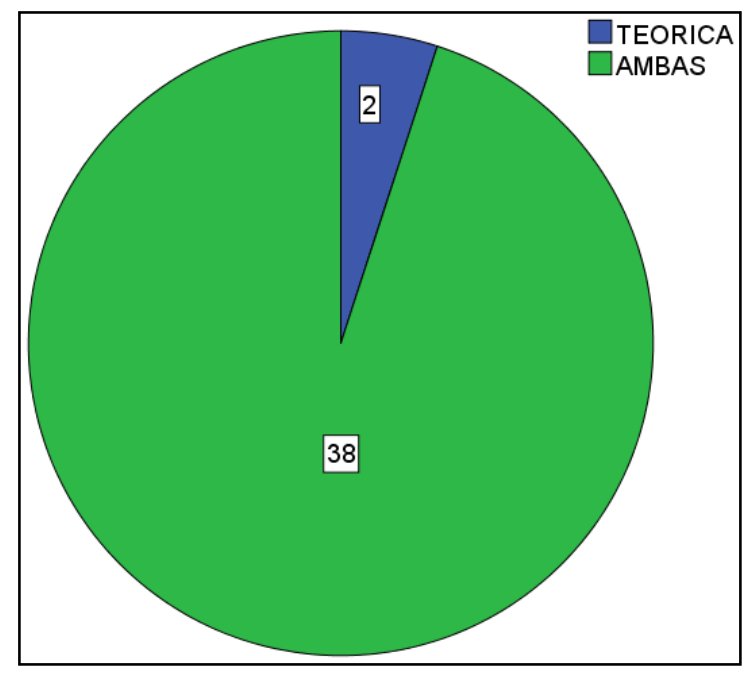

Gráfico 11. Tipo de contenido de las clases de Educación Ambiental 
En vista de la importancia de la Educación Ambienta se le preguntó a los docentes, de acuerdo con su criterio, ¿en qué asignaturas es importante tratar los temas de Educación Ambiental? Los datos obtenidos muestran que 3 de 4 docentes, considera que los temas de Educación Ambiental, deberían estar incluidos en las asignaturas de Biología y Química; pero también consideraron que la asignatura de Educación para la Ciudadanía también debería contener este tema (ver gráfico 12).

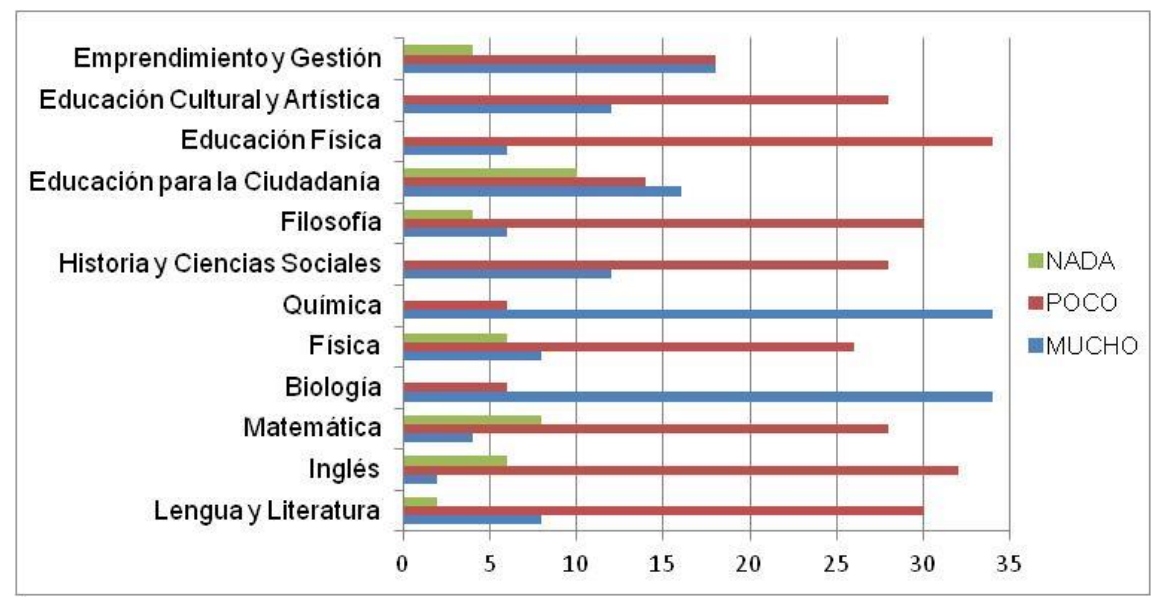

Gráfico 12. Asignaturas que deben tratar los temas de Educación Ambiental

La opinión de los docentes acerca de la responsabilidad social de los estudiantes se observó al preguntar si ¿Cree que los estudiantes tienen una cultura de Responsabilidad Social dentro de la Institución? fue demostrado que de 40 docentes encuestados, 31 docentes consideraron que A Veces los estudiantes muestran una cultura de responsabilidad social $(77.5 \%)$, mientras que 7 docentes consideraron que los estudiantes no muestran una cultura de responsabilidad social $(17.5 \%)$ y 2 docentes consideraron que los estudiantes $\mathrm{Si}$ muestran una cultura de responsabilidad social (5\%) (Ver gráfico 13).

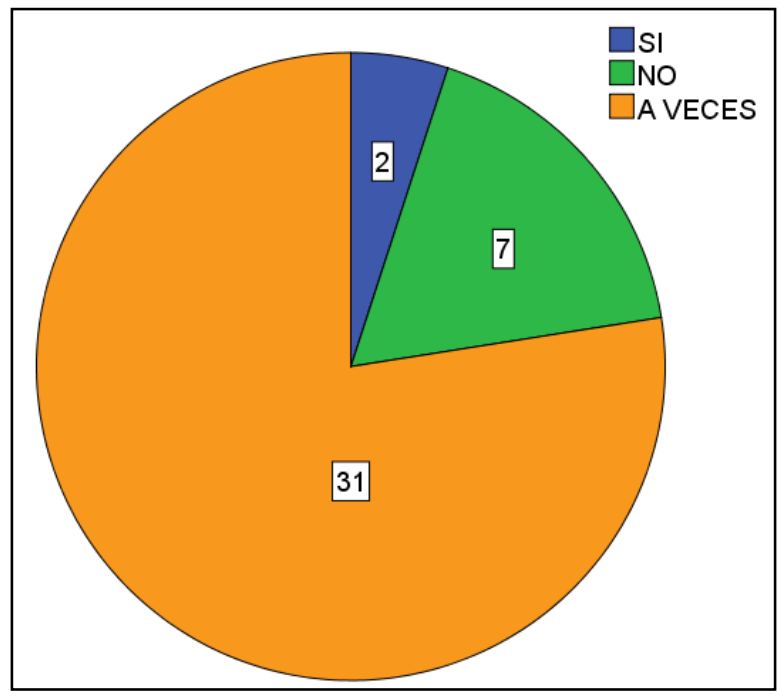

Gráfico 13: Responsabilidad Social de los estudiantes dentro de la Institución. 
Para finalizar con la encuesta a los docentes se les preguntó si consideraban que en la institución se promueva con los estudiantes la realización de actividades específicas de educación ambiental. Según los datos observados, 2 de cada 3 docentes promueven a los estudiantes cuidar el ornato y el medio ambiente de la institución. En lo que respecta al resto de actividades, como agua, aire, energía eléctrica, reciclaje; falta impulsar a los alumnos a cuidar de estas áreas, muy importantes para el ambiente, si esto es comparado con los resultados que arrojaron los estudiantes encuestado a esta pregunta, coinciden plenamente sus respuestas; por lo tanto, se pudo determinar la importancia de proponer los contenidos micro-curriculares en la educación de los estudiantes del BGU (ver gráfico 14).

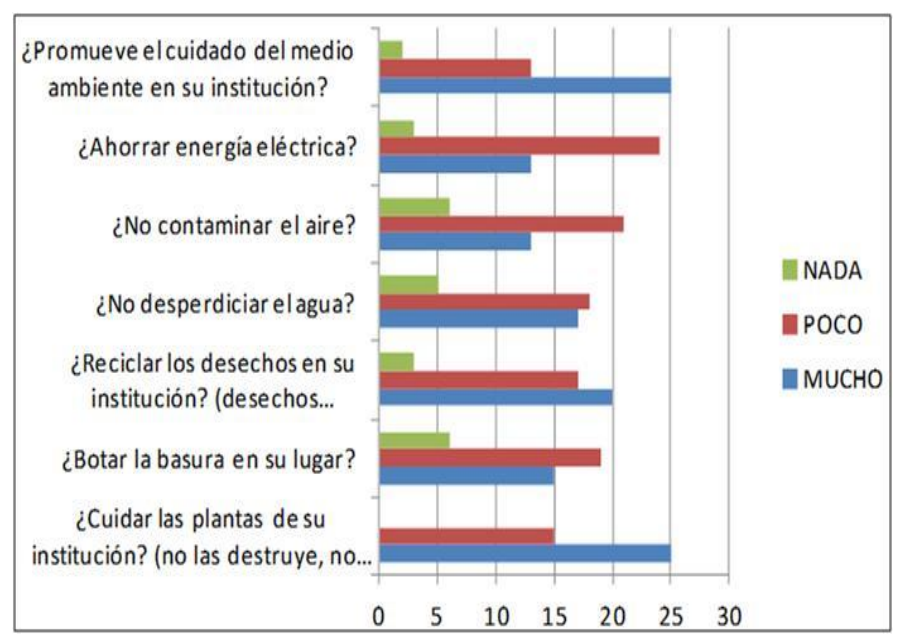

Gráfico 142. Actividades que la institución promueve en los estudiantes.

Los resultados avalan la necesidad de plantear contenidos micro-curriculares de Educación Ambiental y Responsabilidad social ambiental, tanto desde la perspectiva de los estudiantes, como de los docentes, además de la falta de estos contenidos dentro del currículo del BGU. A partir de estos resultados se plantea la propuesta de "Contenidos microcurriculares en educación ambiental, para promover la responsabilidad social en los estudiantes de educación media". En este punto se plantean los antecedentes a la propuesta y la presentación de la propuesta de inclusión de contenidos micro-curriculares en educación ambiental.

Antecedentes. Cabe señalar el análisis del currículo actual que el Ministerio de Educación, maneja para el Bachillerato General Unificado (BGU). Dentro de éste, es importante mencionar que las asignaturas que se dictan en el BGU, se derivan de las materias principales que son consideradas como base, para desprender los contenidos que se enseñarán a los estudiantes. Estas materias principales son: Matemáticas, Lengua y Literatura, Ciencias Sociales y Ciencias Naturales.

La asignatura de Ciencias Naturales, se imparte como tal durante toda la Educación General Básica, dividida en bloques, y estos bloques divididos en varios sub-bloques, que contienen temas relacionados a la asignatura. Una vez culminada la Educación General Básica, los estudiantes pasan al nivel del Bachillerato General Unificado, donde específicamente la asignatura de Ciencias Naturales, desprende tres materias que son: Física, Biología y Química. 
La asignatura de Ciencias Naturales consta de cinco bloques que se imparten durante toda la Educación General Básica, a su vez el Bloque 1 y 2, se divide en cuatro sub-bloques que forman parte de la asignatura de Biología. El bloque tres de la asignatura de Ciencias Naturales, se divide en dos sub-bloques que forman parte de la asignatura de Química y cuatro sub-bloques que forman parte de la asignatura de Física. El bloque cuatro de la disciplina de Ciencias Naturales, también es parte de la asignatura de Física. Y el bloque cinco de la asignatura de ciencias Naturales, se encuentra en cada una de las asignaturas, es decir en Biología, en Química y en Física, hay un sub-bloque más.

En la materia de Ciencias Naturales, se puede evidenciar que no existen contenidos específicos de Educación Ambiental, para lo cual se ha visto necesario plantear algunos contenidos dentro de las asignaturas de Biología y Química, tal y como lo sugieren los docentes encuestados y considerando que según el currículo actual son las materias que guardan estrecha relación con la Educación Ambiental. En las materias de Biología y Química tampoco existen contenidos de Educación Ambiental que promuevan una cultura de Responsabilidad Social.

Presentación de la Propuesta. En la actualidad las personas realizan muchas actividades que generan impactos ambientales, consciente 0 inconscientemente estamos acostumbrados a usar y tirar; a consumir y a obtener ganancias; y a explotar los recursos sin considerar las consecuencias. Todo esto ha llevado a que el Medio Ambiente se encuentre cada vez más debilitado y desmejorado. Y como consecuencia de ello, afectamos a todos los seres vivos.
La Educación Ambiental es interdisciplinaria y necesita el aporte de la química, la física, la estadística, la biología, la geología, la matemática y otras ciencias consideradas duras, para poder explicar mejor los fenómenos y realidades naturales y con suficientes fundamentos presentar alternativas de solución. Por esta razón, la presente propuesta nace de la necesidad de promover la Educación Ambiental en los jóvenes del BGU, planteando contenidos microcurriculares que formen ciudadanos conscientes de la realidad ambiental y actores proactivos en el cuidado y conservación de la naturaleza.

La propuesta presentada a continuación responde al segundo objetivo de este trabajo que es determinar los contenidos microcurriculares de Educación Ambiental necesarios que se requieren incluir para fomentar la Responsabilidad Social, por lo tanto, se presentan contenidos para que conozcan, reflexionen, investiguen y apliquen todos los conocimientos necesarios, con el propósito de convertirse en mensajeros del cuidado ambiental y promotores de mejores condiciones de vida. La presente propuesta está estructurada en plantear dos bloques, uno para la asignatura de Biología y el otro para la asignatura de Química. Se propone la creación de estos bloques, ya que contienen temas específicos de Educación Ambiental, que promueven la Responsabilidad Social con el Medio Ambiente (ver figura 2).

Una vez analizado y revisado el currículo del BGU, se han planteado contenidos que no existen actualmente y se proponen temas prácticos que permitirán a los estudiantes ser propositivos $\mathrm{y}$ activos en el mejoramiento ambiental. 


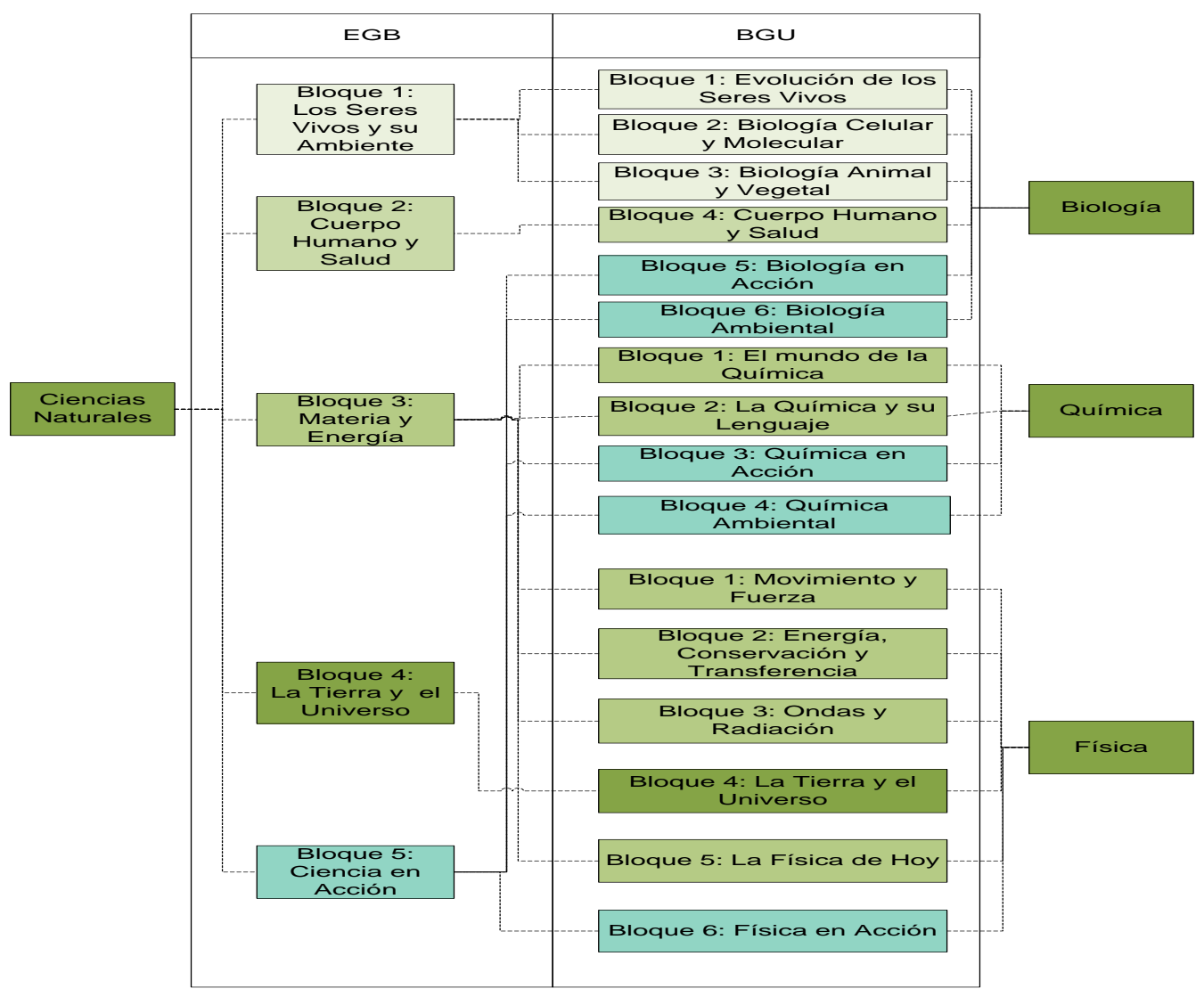

Figura 2. Contenidos de Educación Ambiental dentro del currículo. Fuente: A partir de Ministerio de Educación y Cultura (2016).

A continuación se presentan los contenidos propuestos en las asignaturas de Biología y Química, con cada tema y subtema planteado:

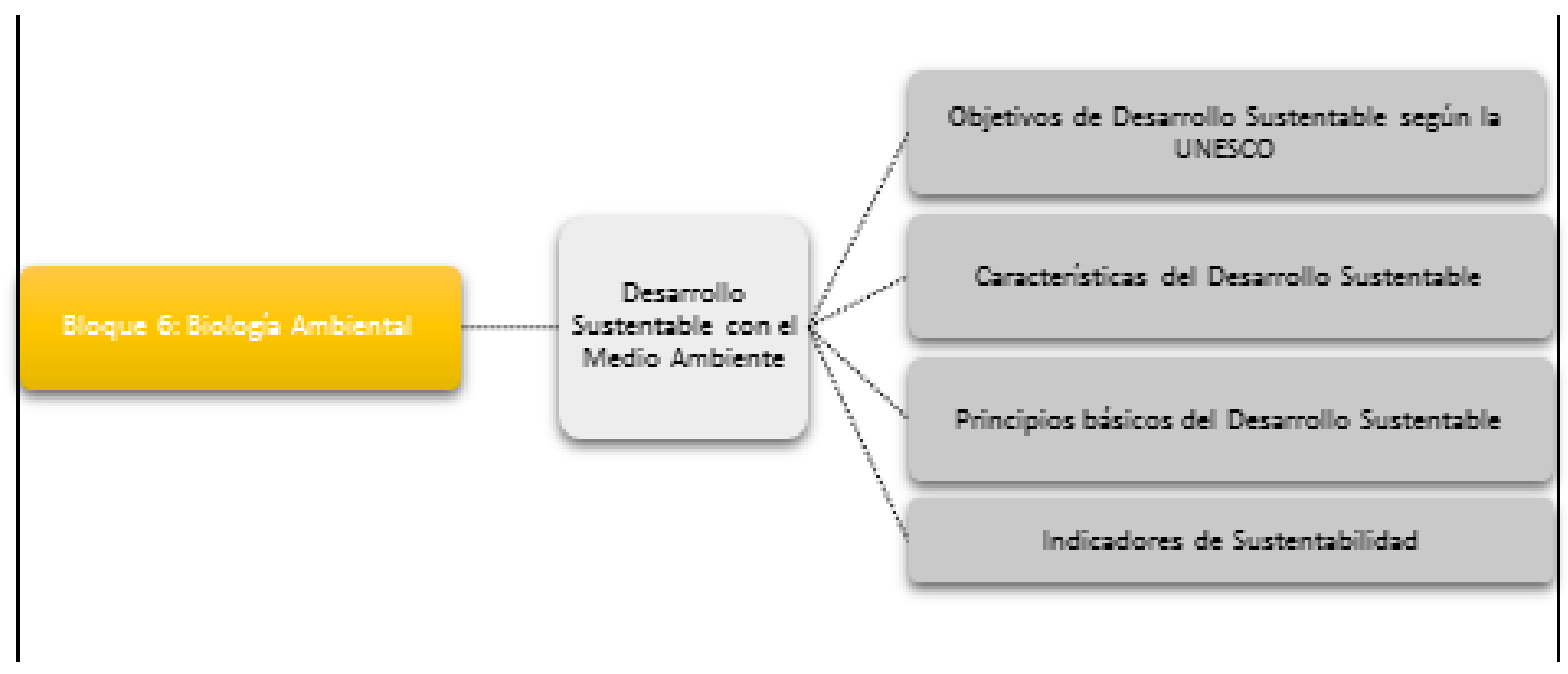

Figura 3. Mapa Conceptual Biología Bloque 6. 
Para la asignatura de Biología, se ha propuesto un nuevo Bloque que se lo ha denominado como Biología Ambiental, dentro del cual constan tres temas. El primer tema que es Desarrollo Sustentable con el Medio Ambiente, como se puede observar en la Figura 3, contiene cuatro subtemas que precisan contenidos esenciales sobre el Desarrollo Sustentable, basados en los problemas ambientales que fueron detallados en el Marco Teórico de esta investigación. Este tema está enfocado, para los estudiantes de Primero de Bachillerato del BGU.

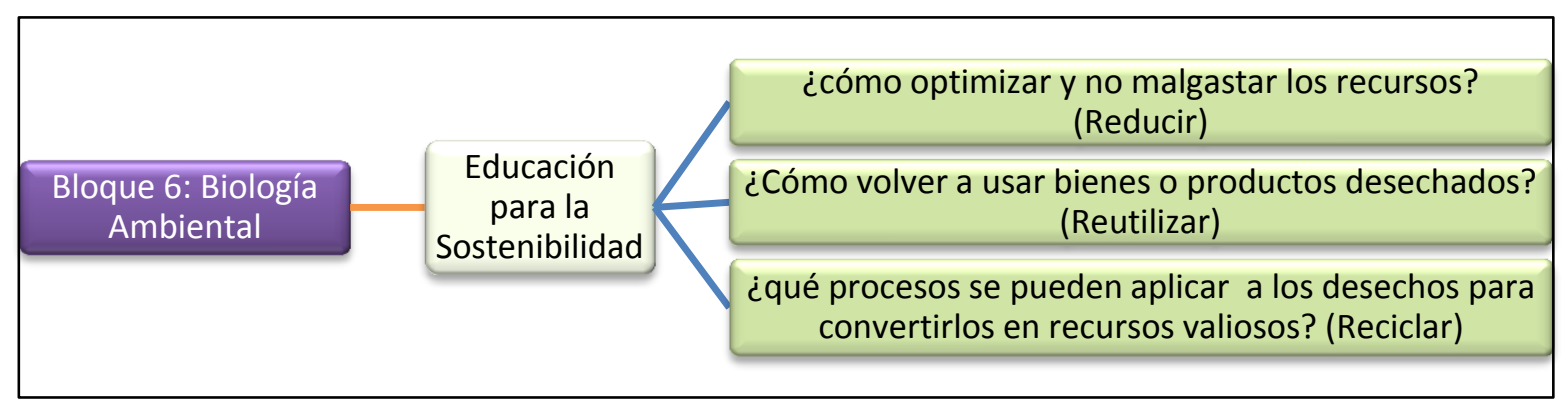

Figura 4. Mapa Conceptual Biología Bloque 5

El segundo tema que forma parte del Bloque 6, se lo ha denominado como Educación para la Sostenibilidad, como se puede observar la Figura 4. Dentro del cual constan tres sub-temas, en donde ya se empieza a poner en práctica los principios de las tres $\mathrm{R}$, (reducir, reutilizar y reciclar). Estos contenidos han sido desarrollados para los estudiantes de Segundo de Bachillerato.

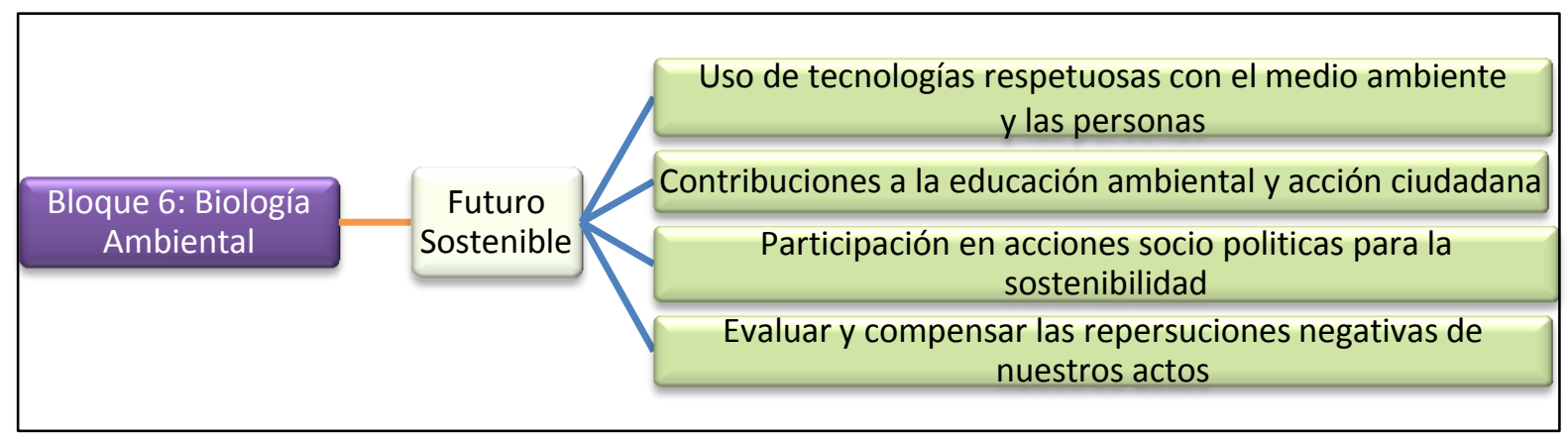

Figura 5. Mapa Conceptual Biología Bloque 6

Y el tercer tema que forma parte del Bloque 6 de Biología, se denomina Futuro Sostenible, como se observa la Figura 5, dentro del cual se plantean cuatro sub-temas que ponen en práctica los conocimientos adquiridos por los estudiantes y realizan actividades que reflexión y concienciación con el medio ambiente; con el propósito de crear una Responsabilidad Social. Estos contenidos están enfocados para los estudiantes del Tercero de Bachillerato. 


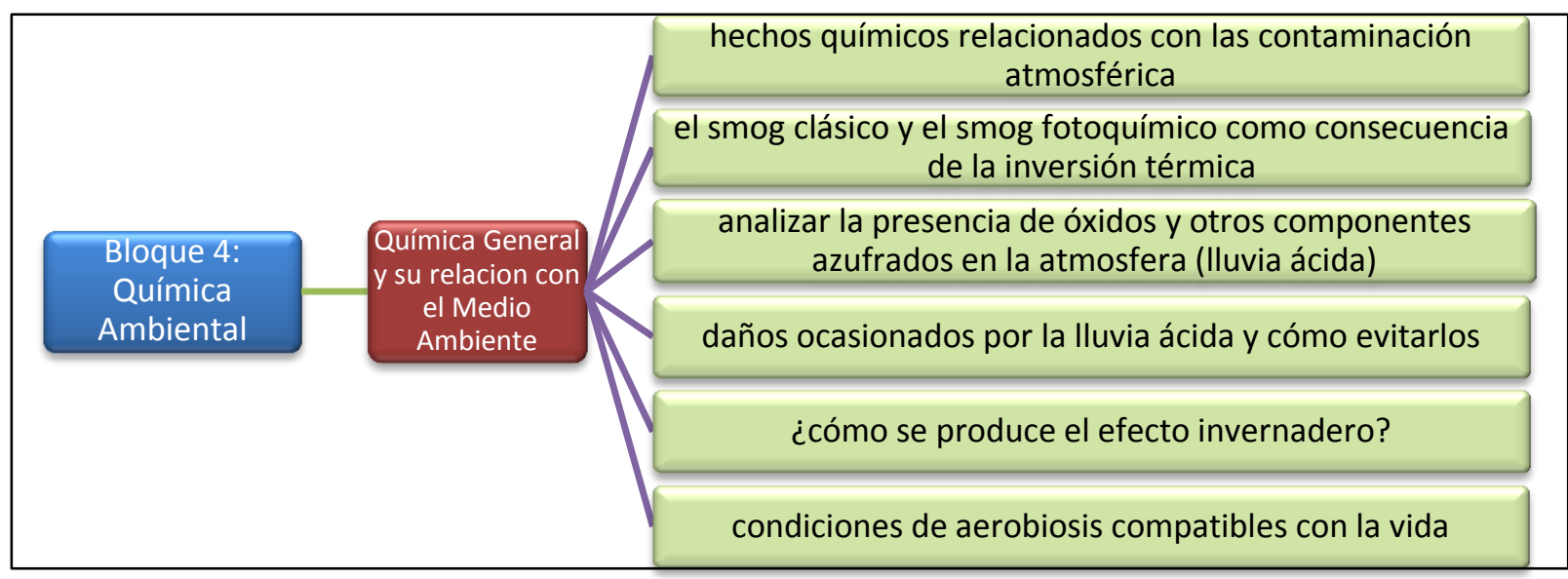

Figura 6. Mapa Conceptual Química Bloque 4

Para la asignatura de Química, se plantea la creación del Bloque 4, denominado como Química Ambiental, dentro del cual se propone el tema Química General y su Relación con el Medio Ambiente, tal como se observa en la Figura $\mathrm{N}^{\circ}$ 6. Los seis sub-temas contenidos, buscan experimentar los efectos producidos en el ambiente, debido a la contaminación y daño medioambiental.

\section{Discusión}

Los resultados de la investigación realizada muestran que los contenidos micro-curriculares no son suficientes en temas de Educación Ambiental y Responsabilidad social con el ambiente en el nivel media de educación en Ecuador, lo que incide en la conducta de los estudiantes limitada a solo colocar la basura en su lugar y el cuidado de las plantas. Estos resultados en el Ecuador, coinciden con otras investigaciones realizadas en Venezuela, en relación a tema ambiental, como por ejemplo con el trabajo realizado por Cayón y Pernalete (2011), denominado "Conciencia Ambiental en el Sistema Educativo Venezolano". Este trabajo se planeó como objetivo determinar el nivel de conciencia ambiental en los alumnos de los subsistemas de Educación Básica, Educación Media y Educación Superior de las instituciones públicas y privadas y los resultados revelan que el nivel de conciencia ambiental de los estudiantes no se corresponde con la realidad, debido a la necesidad de integración de componentes actitudinales, buscar nuevos espacios para la reflexión y la toma de decisiones, así como la responsabilidad en torno al manejo de la conciencia ambiental.

Esta investigación demuestra por una parte una realidad similar a los resultados arrojados en la presente investigación, aun en contextos diferentes, es decir, la conciencia sobre educación ambiental de los estudiantes tanto en el Ecuador como en Venezuela, no se corresponde con el tipo de conciencia que requiere la sociedad actual, ello es resultado en buena medida de la relación con la educación ambiental recibida en las instituciones educativas, en el caso Ecuatoriano. Por otra parte, la investigación de Cayón Padilla y Pernalete (2011) contribuyó a proponer la creación de los temas que se plantean para la asignatura de Biología, como Biología Ambiental, y dentro de éste, el subtema "Desarrollo Sustentable con el Medio 
Ambiente", para promover conductas ambientalistas en los estudiantes, así como también crear espacios para la reflexión.

Otra investigación desarrollada por Tello y Pardo (1996), titulada: "Educación Ambiental: Teoría y Práctica. Presencia de la Educación Ambiental en el nivel medio de Enseñanza de los Países Iberoamericanos", afirma la importancia que tienen los proyectos de reforma educativa en torno al tema de Educación Ambiental, estos proyectos suponen un avance en la integración curricular en todos los niveles superiores de la enseñanza, sin embargo, los resultados de esta investigación demuestran que en el nivel medio de educación, la educación ambiental se limita a ciertas asignaturas como las Ciencias Naturales y Sociales, las cuales para impartir el conocimiento incrementan su horario, en alguna medida.

Otros resultados en cuanto a los diseños curriculares, es que en los países de América Latina, se introduce el tema ambiental para bachilleratos específicos dedicados a esta temática, como por ejemplo los bachilleratos de Ecología y Medio Ambiente. Este trabajo encontró que las reformas no tienen en cuenta la importancia de la incorporación de la Educación Ambiental en cuanto a los contenidos en las asignaturas. Todos estos hallazgos del trabajo de Tello y Pardo (1996) son cónsonos con lo encontrado en los resultados de la presente investigación, en cuanto al tema de la insuficiencia de contenidos micro-curriculares de Educación Ambiental y prácticamente de disciplinariedad asignada a este tema.

Por otra parte, la investigación de Tello y Pardo (1996) coadyuvó a ubicar las asignaturas (Biología y Química) en las cuales se puede implementar los contenidos de Educación Ambiental, por lo tanto, la formación ambiental es vital para contribuir a una sólida educación ambiental como problema profesional de la práctica escolar cuya solución conduzca a una correcta interacción hombre-naturalezasociedad en la que el hombre sea capaz de utilizar racionalmente los recursos de la naturaleza y al mismo tiempo desarrolle actitudes y valores en función de su protección y empleo para el mejoramiento de las relaciones que se establecen en la sociedad.

Otra investigación que arroja resultados similares al presente trabajo, fue la de Jiménez y Zambrano (2013), en su investigación titulada "Guía Didáctica de Educación Ambiental para Segundo Año de Bachillerato". Este trabajo se realizó con el propósito de diseñar e implementar una Guía Didáctica en material de Educación Ambiental, dada las deficiencias en los procesos de enseñanza-aprendizaje desarrollados en la Institución Educativa. Los resultados de la investigación de Jiménez y Zambrano (2013) dan cuenta que los docentes están poco conformes como se imparten los contenidos en materia de Educación Ambiental, por su parte a los estudiantes les gusta poco la forma como se imparte la Educación Ambiental en la Institución, tanto docentes como estudiantes afirman que poseen conocimiento limitados en cuanto al tema.

Estos resultados dan cuenta del déficit de contenidos curriculares en el tema ambiental y las limitaciones de los docentes y estudiantes en el manejo del tema, por lo tanto, son aspectos que al igual que el presente estudio, muestran déficit en el manejo de la Educación Ambiental en la Educación Media. Por otra parte, del trabajo de Jiménez y Zambrano (2013) se pudo obtener los contenidos que se plantean en la asignatura de Biología, con el tema Biología Ambiental y los subtemas: Educación para la sostenibilidad y Futuro Sustentable. También se obtuvieron los temas de la asignatura de Química, con el tema "Químicas Ambiental" con el subtema Química General y su relación con el Medio Ambiente. 
Los trabajos anteriores demuestran que el tema déficit en el desarrollo de la Educación Ambiental en el nivel medio de enseñanza, aún permaneces vigente, aun cuando se han realizado diversas propuestas de reforma curricular en los países de América Latina. Asimismo confirma la Organización de las Naciones Unidas (2001) cuando comunican que las actividades orientadas a integrar el tema del medio ambiente en los planes de desarrollo (eso incluye los planes educativos) y los procesos de toma de decisiones, tendieron a no llegar muy lejos; aunque se considera que se avanzó en aspectos científicos y técnicos, continuó la evasión del tema ambiental en el plano político de modo que los problemas ambientales se continuaron agravando, como el deterioro de la capa de ozono, el calentamiento de la tierra, la degradación y pérdida de los bosques, así que debido a estas y otras razones expuestas desde el inicio, es la pertinencia de esta investigación realizada.

\section{CONCLUSIONES}

Se concluye que existe insuficiencia de contenido de educación ambiental y responsabilidad social con el ambiente en educación media, evidente tanto a nivel curricular formal como en la realidad empírica manifestada por estudiantes y docentes, por lo tanto, se requiere la introducción de contenidos micro-curriculares o subtemas en los textos de estudio del bloque de Ciencias Naturales y las asignaturas de Biología y Química, ya que en estas asignaturas no existe contenido microcurricular en Educación Ambiental y esto se logra a partir de la toma de conciencia tanto de docentes, como de las instituciones educativas y las autoridades del Ministerio de Educación en cuanto al cuidado con el medio ambiente dado en base a una modificación curricular, se recomienda por lo tanto, a los docentes de estas asignaturas emprender una labor de toma de consciencia de la comunidad educativa para impulsar los cambios requeridos ante las instancias del Ministerio de Educación.

\section{REFERENCIAS}

Albert Gomez, M. J. (2007). La investigacion educativa: claves teoricas (Primera ed.). (J. M. Cejudo, Ed.) Madrid: España

Alea, A. (2005). Breve historia de la educación ambiental: del conservacionismo hacia el desarrollo sostenible. Revista Futuros. Revista Latinoamericana y Caribeña de Desarrollo Sostenible., 3(12), 1-8. Obtenido de

http://ftp.murciaeduca.es/programas_ed ucativos/Nuevo1/RECesenred/historiaed ucacionambiental.pdf

Avendaño, W. (2012). La Educación Ambiental (EA) como herramienta de la Responsabilidad Social (RS). (U. d. Manizales, Ed.) Revista Laguna Azul(35), 94-115.

doi:https://doi.org/10.17151/luaz.2012.3 5.7

Benavides, R. (2014). La Planificación de la Educación Superior desde la visión de la Responsabilidad Social Universitaria. Ambato, Tungurahua, Ecuador: PUCESA. Pontificia Universidad Católica del Ecuador Sede Ambato

Carneiro, M. (2004). La Responsabilidad social corporativa interna: la "nueva frontera" de los recursos humanos. Madrid, España: ESIC Editorial

Cayón, A. J., y Pernalete, J. (2011). Conciencia Ambiental en el Sistema Educativo Venezolano. (U. R. (URBE), Ed.) REDEHCS. Revista electrónica de Humanidades, Educación y Comunicación Social, 11(6), 163-186. Obtenido de http://ojs.urbe.edu/index.php/redhecs/a rticle/view/253

Da Ros, G. (1995). La contaminación de aguas en Ecuador: una aproximación económica. Abya Yala. Recuperado el 20 de abril de 2017, de https://books.google.es/books?hl=esylr= yid=rPQrAHRxzyYCyoi=fndypg $=$ PA5ydq= 
En+el+Ecuador,+se+ha+evidenciado+el+ mal+uso+de+los+recursos+naturales+a+t rav\%C3\%A9s+de+la:+tala+indiscriminad $\mathrm{a}+\mathrm{de}+$ bosques,+contaminaci\%C3\%B3n+d e+r\%C3\%ADos,+inadecuado++tratamient o+de

Gutiérrez, J., y Pozo, T. (2006). Modelos Teóricos Contemporáneos y marcos de fundamentación de la Educación Ambiental para el Desarrollo Sostenible. Revista Iberoamerocana de Educación, 2168

Jiménez, S., y Zambrano, E. (2013). Diseño $e$ implementación de una guía didáctica de educación ambiental para segundo año de bachillerato en el Colegio Nacional Salcedo. Escuela Superior Politénica de Chimboraz. Riobamba: Escuela Superior Politénica de Chimborazo. Recuperado el 15 de febrero de 2018, de http://dspace.espoch.edu.ec/handle/123 $456789 / 2494$

Ministerio de Educación y Cultura. (marzo de 2016). Curriculo de Educación Básica y $B G U$. Recuperado el 10 de abril de 2017, de Miniosterio de Educación: https://educacion.gob.ec/wpcontent/uploads/downloads/2016/03/B GU1.pdf
Noboa, A. (2003). Desarrollo sustentable en la República del Ecuador. Ministerio de Medio Ambiente., Quito. Recuperado el 25 de enero de 2017, de https://s3.amazonaws.com/academia.edu .documents/50541244/ecuador-

desarrollo_sustentable.pdf?responsecontent-

disposition=inline $\% 3 \mathrm{~B} \% 20$ filename $\% 3 \mathrm{D}$

Pagina_1_de_12.pdfyX-Amz-

Algorithm=AWS4-HMAC-SHA256yX-AmzCredential=AKIAIWOWYYGZ2Y53UL3A\% 2F20200219\%2Fus-east-

Paucar, L. E. (2012). La Educación Ambiental como contenido curricular en el Sistema Educativo Ecuatoriano y su aplicación a Estudiantes del $7^{\circ}$ año de Educación General Básica, para la conservación del Medio Ambiente saludable en el futuro. Universidad Complutense de Madrid. Madrid: Universidad Complutense de Madrid

Tello, B., y Pardo, A. (1996). Presencia de la Educación Ambiental en el nivel medio de enseñanza de los países iberoamericanos. Revista iberoamericana de Educación.(11), 171-194.

doi:https://doi.org/10.35362/rie1101160 